\title{
LIBERDADE: UMA RELAÇÃO ENTRE CÂNON E DIALÉTICA NA CRÍTICA DA RAZÃO PURA
}

\author{
Nilmar Pellizzaro ${ }^{1}$ \\ Universidade Federal de Santa Catarina (UFSC) \\ (iD) https://orcid.org/0000-0001-9564-5474
}

\begin{abstract}
RESUMO:
O presente estudo investiga a consistência entre as afirmações da Dialética e as do Cânon acerca do problema da liberdade e o faz através de uma análise comparativa de três interpretações, mostrando por que duas delas (Carnois e Allison) seriam equivocadas, e, uma terceira (Esteves), defensável. Carnois aponta que haveria uma incompatibilidade entre Dialética e Cânon ao considerar que a liberdade do Cânon seria uma liberdade limitada e empírica, enquanto que, na Dialética, teria uma espontaneidade absoluta. Allison considera que os textos seriam compatíveis, embora ambos apresentem uma liberdade prática relativa e ambígua (dependente de um estímulo sensível), e por isso haveria uma moralidade pré-crítica na $K r V$. A interpretação de Esteves nos parece a mais sustentável e permite perceber a coerência e a contemporaneidade dos textos (ambos apresentam a liberdade com espontaneidade absoluta), mostrando que, embora a liberdade prática seja uma liberdade relacional (aplicada a seres humanos e por isso em contato com o empírico), ela não é um conceito empírico, mas híbrido.
\end{abstract}

PALAVRAS-CHAVE: Kant; Dialética; Cânon; Liberdade transcendental; Liberdade prática.

\section{FREEDOM: A RELATIONSHIP BETWEEN CANON AND DIALECTIC IN THE CRITIQUE OF PURE REASON}

\begin{abstract}
:
The current study investigates the consistency between the claims of the Dialectic and those of the Canon concerning the problem of freedom, and does so through a comparative analysis of three interpretations, showing why two of them (Carnois and Allison) would be mistaken, and a third (Esteves), defensible. Carnois points out that there would be an incompatibility between Dialectic and Canon in considering that the freedom of the Canon would be a limited and empirical freedom, whereas in the Dialectic it would have an absolute spontaneity. Allison believes that the texts would be compatible, although both present relative and ambiguous practical freedom (dependent on a sensitive incentive), and therefore there would be a precritical morality in $K r V$. Esteves's interpretation seems to us to be more sustainable and allows us to understand the coherence and contemporaneity of texts (both present freedom with absolute spontaneity), showing that, although practical freedom is a relational freedom (applied to human beings and therefore in contact with the empirical), it is not an empirical but hybrid concept.
\end{abstract}

KEYWORDS: Kant; Dialectic; Canon; Transcendental freedom; Practical freedom.

\footnotetext{
${ }^{1}$ Doutorando (bolsista CAPES) em Filosofia pela Universidade Federal de Santa Catarina (UFSC), Santa Catarina - Brasil, com pesquisa em Kant na área de Ética e Filosofia Política. E-mail: nilpellizza@gmail.com
}

PELLIZZARO, Nilmar. Liberdade: uma relação entre cânon e dialética na Crítica da razão pura. Griot : Revista de Filosofia, Amargosa, Bahia, v.16, n.2, p.169-187, dezembro/2017. 


\section{Introdução}

Neste estudo abordaremos o papel da liberdade no Cânon da razão pura a partir da relação com o conceito de liberdade apresentado na Dialética. Analisaremos se, de fato, as afirmações a seu respeito na Dialética se coadunam ou não com aquilo que dela é afirmado no Cânon. A ideia fundamental não é apresentar uma tese original, mas dialogar com três perspectivas interpretativas mostrando por que uma delas é mais sustentável, bem como os aspectos frágeis das outras duas. Veremos que a primeira leitura - Carnois - considera como incompatíveis as afirmações da Dialética em relação às do Cânon, apontado que o conceito de liberdade apresentado pelo último é pré-crítico e por isso deve ter sido escrito anteriormente à Dialética. A segunda proposta - Allison - considera que as afirmações da Dialética seriam compatíveis com as do Cânon, porém veicula um conceito de liberdade prática ambígua e relativa em relação à afetação dos impulsos da sensibilidade. A terceira leitura - Julio Esteves - também considera compatível a Dialética com o Cânon, porém defende um conceito de espontaneidade absoluta para a liberdade e mostra que a liberdade prática não é empírica (como pensam Allison e Carnois), mas híbrida. De nossa perspectiva, a última leitura é mais coerente e sustentável e nos permite perceber uma unidade e contemporaneidade entre os textos da $\mathrm{KrV}$.

\section{A liberdade como um problema no contexto da relação entre Cânon e Dialética}

Na Dialética da $K r V$ Kant chega à conclusão de que a razão, no seu uso teórico, chegou ao seu próprio limite, e que a ideia de liberdade não poderia ser afirmada positivamente, não sendo possível conhecer qualquer objeto definido por este conceito, já que se tratava de uma ideia cujo objeto transcendia a experiência possível, devendo ser tomado apenas reguladoramente, no sentido de se poder apenas pensar novos inícios dentro da série, mas sem poder saber que se é livre, nem em que consiste tal liberdade. Além disso, chega à conclusão de que, do ponto de vista teórico, seria pelo menos possível pensar que a liberdade poderia coexistir com a causalidade natural num mesmo fenômeno, sem trazer problemas à regularidade da natureza e sem violar a lei da experiência, pois a liberdade é pensada como um conceito puramente problemático e dialético. Nas palavras de Kant, "a liberdade é aqui tratada unicamente como uma ideia transcendental mediante a qual a razão pensa iniciar absolutamente a série das condições no fenômeno através daquilo que não é condicionado pelos sentidos [...]" ( $K r V$, B586).

Por outro lado, não se poderia também afirmar a impossibilidade de sua existência e isto já seria um grande ganho em termos teóricos, pois deixava aberta a possibilidade de que ela eventualmente poderia ser algo real. Por isso, de um ponto de vista lógico, ela se apresenta como um conceito possível, embora nossa estrutura interna de conhecimento, que é a priori e espaço-temporal, não nos permita ir além da experiência possível para conhecê-la e afirmá-la assertivamente. Mesmo assim, é possível pensarmos que a liberdade exerça uma causalidade (que se expressa por meio do dever) ainda que teoricamente não possamos demonstrá-la. 
Se a perspectiva teórica da razão impõe limites ao conhecimento da causalidade noumênica, Kant então se propõe a demonstrar que, no âmbito prático, a razão teria mais sucesso. Eis então a peculiaridade do Cânon, que trata justamente de mostrar que é possível um uso positivo para a ideia de liberdade. Por isso, se o problema da Dialética era verificar a possibilidade de pensar a liberdade sem contradição com a causalidade natural, agora, no Cânon, trata-se de demonstrar que esta liberdade é possível no domínio prático. Se no uso teórico, o objeto da liberdade permanecia um conceito vazio (um objeto "x"), agora, no Cânon, Kant quer pensá-lo a partir da experiência para assim poder atribuir-lhe um objeto. Conforme ele expressa no capítulo segundo da Doutrina transcendental do método,

a razão pressente objetos que se revestem de um grande interesse para ela. Enceta o caminho da simples especulação para se aproximar destes objetos; estes últimos, no entanto, se esquivam dela. Presumivelmente poderá esperar melhor sorte na única senda que ainda lhe resta, a saber, a do uso prático $(K r V$, B824).

Assim, por um Cânon Kant entende "[...] o conjunto dos princípios a priori do uso correto de certas faculdades de conhecimento em geral" ( $K r V$, B824). Como no âmbito teórico o uso sintético da ideia de liberdade se mostrou impossível (por tratar-se de um conhecimento dialético), assim, se há algum uso correto desta ideia este uso só pode ser o prático, em torno do qual será possível elaborar um Cânon. Conforme Kant, "prático é tudo aquilo que é possível através da liberdade" ( $K r V, \mathrm{~B}$ 828), de modo que suas leis devem ser consideradas leis práticas puras, isto é, leis morais. Somente estas admitem um Cânon da razão em seu uso prático, visto que o seu fim é dado a priori pela razão. Nisto diferenciam-se das leis pragmáticas, cujos fins são dados pelos sentidos, não sendo a priori e, portanto, também não devem ser consideradas leis puras e sim pragmáticas $(K r V, B 829)$.

Kant apresentou, na Dialética, a liberdade transcendental negativamente como sendo aquela liberdade não condicionada por causa anterior que a determine quanto ao tempo ( $K r V$, B582), e positivamente como sendo a faculdade de iniciar um estado espontaneamente e de forma absoluta ( $\mathrm{KrV}, \mathrm{B} 561)$; Contudo, Kant dá um passo adiante e afirma que a liberdade pode ser prática, isto é, que a razão pode determinar o arbítrio independentemente dos impulsos da sensibilidade.

\footnotetext{
A liberdade no sentido prático é a independência do arbítrio frente à coerção pelos impulsos da sensibilidade. Com efeito, um arbítrio é sensível na medida em que é afetado patologicamente (por motivação da sensibilidade); denomina-se animal (arbitrium brutum) quando ele pode ser patologicamente necessitado. Apesar de consistir num arbitrium sensitivum, o arbítrio humano não é um arbitrium brutum, mas sim liberum, pois ao homem é inerente um poder para determinar-se espontaneamente, independentemente da coerção por impulsos sensíveis ( $K r V, \mathrm{~B} 562)$.
}

Para Kant, a natureza inanimada ou meramente animal possui um arbitrium brutum, que segue o mecanismo da natureza, não sendo possível atribuir-lhe nenhuma liberdade, já que é patologicamente necessitado. Exclusivamente no 
homem, por seu arbitrium liberum, que é afetado, mas não patologicamente determinado pelos impulsos da sensibilidade, temos que pressupor um caráter inteligível em sua ação, o qual, expressa certas faculdades, como entendimento e razão, que se distinguem de todas as formas empiricamente condicionadas, já que a razão pondera os seus objetos segundo ideias, e determina que o entendimento possa fazer uso dos conceitos puros ( $K r V$, B575). Conforme Kant, "o dever expressa um tipo de necessidade e de conexão com fundamentos que não ocorrem alhures com toda a natureza" $(K r V, B 575)$. A natureza só pode revelar o que é. Não pode dar a conhecer que algo deva ser, de tal modo que, se houver algum dever, ele não pode ser proveniente da natureza. Assim, ao ter em vista o dever e os imperativos, é necessário admitirmos uma efetiva causalidade da razão. É por meio do dever que a razão expressa uma ordem diferente da ordem natural, e pode-se dizer que, por seu caráter inteligível, ela inicia espontaneamente uma nova série independentemente dos impulsos da sensibilidade. Nas palavras de Kant, "[...] com toda a espontaneidade ela [a razão] se constrói uma ordem própria segundo ideias, à qual adapta as condições empíricas e segundo a qual declara necessárias até as ações que ainda não ocorreram e que talvez nem venham a ocorrer" $(K r V$, B576 - colchetes acrescentado). E aqui Kant quer expressar algo mais que um mero conceito problemático, não contraditório, pensado enquanto liberdade transcendental. Segundo ele, haveria alguns "sinais" que nos permitem reconhecer uma ação espontânea da liberdade, já que tais ações manifestariam um dever (seja quando o dever é cumprido, seja quando não o é, o que denotaria claramente sua violação, ressaltando a consciência faltosa do violador) que não poderia ser pensado se somente levássemos em conta a natureza. Contudo, tendo em vista os limites da razão no âmbito teórico, Kant não pôde elaborar nenhuma dedução da liberdade prática na Dialética, mas apenas postula que ela poderia ser real, assumindo antecipadamente uma positividade para este conceito. Esta "prova" seria fornecida então pelo Cânon, por meio da experiência.

Ocorre que esta mesma definição da liberdade prática é retomada no Cânon e Kant a reafirma nos mesmos termos da Dialética, postulando que há no homem um arbitrium liberum que o diferencia dos animais e lhe permite sobrepor-se às determinações patológicas da sensibilidade e agir por motivações que são representadas exclusivamente pela razão $(K r V, B 829-30)$. O que é notório em ambas os textos é que a liberdade prática é sempre definida em oposição à sensibilidade, isto é, para que a razão exerça uma causalidade ela deve afastar-se dos móbeis sensíveis, evidenciando que há, em sua causalidade, um caráter de espontaneidade. Além disso, Kant afirma, na Dialética, que a supressão da liberdade transcendental aniquilaria toda a liberdade prática $(K r V, B 562)$, de modo que haveria ali uma total dependência da liberdade prática em relação à transcendental, sendo que a inexistência desta última, consequentemente, aniquilaria a possibilidade da primeira.

Disto se depreende que na Dialética a liberdade prática possui um caráter inteligível que lhe é fornecido pela transcendental, pois, do contrário, ela poderia ser considerada uma mera causalidade natural, já que as ações humanas, no que diz respeito ao caráter empírico, em nada contrariam a natureza. Ora, ao definir, no Cânon, a liberdade prática nos mesmos termos da Dialética, é de supor-se que Kant 
está pressupondo a mesma dependência dela em relação à transcendental. Contudo, em virtude do contexto do Cânon ter um interesse prático e não especulativo, Kant afirma: "[...] porei de lado aqui este conceito em seu significado transcendental, o qual não pode ser empiricamente pressuposto como um fundamento explicativo dos fenômenos, mas constitui ele mesmo um problema para a razão" ( $K r V$, B829-30). Por que Kant deixa de lado a liberdade transcendental no texto do Cânon? Esta atitude pareceria revelar uma falta de coesão com o texto da Dialética, já que, nesta última, ambas as liberdades estavam intimamente conectadas. Este seria o primeiro problema a ser analisado.

Um segundo problema surge poucas linhas abaixo quando Kant afirma que "a liberdade prática pode ser provada por experiência" ( $K r V$, B830). Ora, lembremos que da experiência somente conhecemos os fenômenos que nos são dados pelas formas a priori do espaço e do tempo. Segundo a Dialética, a liberdade, em sendo uma ideia da razão e dada sua natureza inteligível, poderia ser apenas pensada como tendo causalidade no mundo sensível, mas jamais provada por experiência.

Um terceiro problema surge poucas linhas depois quando Kant afirma:

Conhecemos, pois, a liberdade prática pela experiência como sendo uma das causas naturais, a saber, uma causalidade da razão na determinação da vontade; enquanto isto, a liberdade transcendental exige uma independência desta mesma razão [...] frente a todas as causas determinantes do mundo sensível, parecendo nesta medida contrária à lei da natureza e portanto à experiência possível, e permanecendo pois um problema" (KrV, B831).

Em que pesem as dificuldades de interpretação dos dois primeiros problemas, este terceiro parece contradizer mais frontalmente as teses da Dialética, pois lá a liberdade prática exercia uma causalidade inteligível, quando aqui parece ser reduzida à causalidade natural e perder o caráter absoluto de sua espontaneidade. Seria possível que Kant tenha caído em tantas inconsistências, retrocedendo a um estágio pré-crítico? Vejamos o que nos revelam as interpretações seguintes, a começar por Carnois, o qual vê uma incompatibilidade entre o texto da Dialética e do Cânon.

\section{Carnois: a incompatibilidade entre o Cânon e a Dialética}

Carnois aponta que, no âmbito teórico, Kant não estabeleceu a realidade da liberdade como uma faculdade que contém a causa dos fenômenos no mundo sensível, mas apenas chegou a um conceito problemático e não contraditório. Isto implica que, embora o conceito de liberdade transcendental permaneça vazio, seu objeto deve ser distinguido de um nada negativo, ficando assim a questão insolúvel no domínio teórico (CARNOIS, 1987, p. 18-19). Segundo ele, há na Dialética uma estreita relação entre a liberdade transcendental e a liberdade prática, de modo que esta última é ali representada como um dos ingredientes da primeira. De fato, ali a liberdade prática se mostra na experiência através de uma apreensão psicológica imediata toda vez que a vontade impõe seu veto sobre as impressões sensíveis, 
demonstrando assim uma independência da razão em relação às causas naturais (CARNOIS, 1987, p. 24-25). Por isso, a liberdade prática inclui nela um elemento de espontaneidade dado pela liberdade transcendental, o que lhe permite pensar uma ação com total independência dos móbeis da sensibilidade, sendo determinada essencialmente pelas leis da razão. Assim, Carnois não vê problemas na descrição da liberdade prática na Dialética, uma vez que a possibilidade da razão determinar o arbítrio está garantida pela espontaneidade do seu caráter que lhe é dado pela liberdade transcendental. Este plus da espontaneidade da liberdade transcendental é o que permite à razão sobressair em relação à natureza e determinar o arbítrio livremente.

Ocorre que também no Cânon Carnois considera que a liberdade prática pode ser conhecida por meio de uma apreensão psicológica. Porém, enquanto na Dialética ela era definida como independência dos móbeis sensíveis, no Cânon torna-se "uma das causas naturais", o que, no entender de Carnois, caracterizaria uma "contaminação" de sua causalidade inteligível com os móbeis da sensibilidade, demonstrando assim que não se trata de uma liberdade absolutamente pura. Com esta imersão da liberdade prática no âmbito das causas naturais, haveria, no Cânon, um rompimento da relação entre a liberdade prática e a transcendental, já que esta última exige uma absoluta independência do mundo sensível, enquanto que a liberdade prática estaria inserida na causalidade natural, na tentativa de livrar-nos da determinação estritamente sensível. Essa perda de vínculo com a liberdade transcendental faz com que liberdade prática perca aquele plus de absoluta espontaneidade que lhe era transmitido transcendental na Dialética e assim elas tornam-se "estranhas" entre si, já que uma seria um conceito problemático da razão, enquanto a outra um fato demonstrado por experiência como uma das causas naturais. (CARNOIS, 1987, p.29).

Disto o autor conclui que não há qualquer congruência entre a doutrina da moralidade apresentada no Cânon e aquela da Dialética, porque o conceito prático de liberdade do Cânon é um conceito empírico ligado à natureza, enquanto que, na Dialética, estava ligado à liberdade transcendental que lhe garantia um caráter de espontaneidade absoluta. Por isso, o texto da Dialética seria mais coerente com a moralidade madura de Kant desenvolvida nos textos posteriores, devendo ter sido escrito posteriormente ao Cânon. Neste caso, toda a teoria moral ${ }^{2}$ desenvolvida no Cânon seria pré-crítica e o imperativo moral não seria sintético e incondicionado, já

\footnotetext{
2 Defendemos (contrário a autores como ALLISON, 1990; ALMEIDA, 1997; CARNOIS, 1987; SMITH, 1996, os quais sugerem que a moralidade desenvolvida no Cânon seria uma moralidade heterônoma e pré-crítica em relação àquela de obras como a $G M S$ e a $K p V$ ) que, embora não haja uma teoria moral plenamente lapidada na $K r V$ (pois Kant não havia fundamentado o imperativo categórico como um princípio universal que expressa a autonomia da vontade) Kant já dispõe dos principais conceitos de seu pensamento moral para apresentar uma moralidade crítica. E dentre estes a ideia de "merecimento de ser feliz" que Kant denomina de "lei da moralidade" como contraposta à regra de prudência. Kant demonstra que a disposição moral é a condição para participar da felicidade, isto é, que a necessidade interna presente nas leis morais possui força suficiente para nos obrigar a agir. Por isso que ele diz: "não consideraremos as ações como obrigatórias pelo fato de serem mandamentos de Deus; ao contrário, encará-las-emos como mandamentos divinos por estarmos internamente obrigados a cumpri-las" ( $\mathrm{Kr} V$, B847).
} 
que o bem supremo seria o fundamento da moralidade e não a lei moral: "se você deseja o bem supremo, então age como deves agir" (CARNOIS, 1987, p. 27; 29).

Segundo Carnois, na Dialética a liberdade prática atua com independência das causas naturais, ao passo que no Cânon ela própria é uma causalidade natural, passível de ser conhecida por experiência. Assim, a liberdade prática apresentada no Cânon é ambígua. Tal ambigüidade deriva de uma posição intermediária que ela ocupa entre a natureza e a liberdade transcendental, na qual supostamente deveria estar fundada. Mas, como o conceito transcendental da liberdade é um conceito problemático, a liberdade prática acaba herdando dele algumas dificuldades, uma vez que, de uma possibilidade que é somente lógica de um conceito cosmológico, não se pode passar a uma possibilidade real. Permanece, portanto, um espaço vazio dentro do conceito prático, que eventualmente a liberdade transcendental poderia ocupar se o seu objeto pudesse ser estabelecido na experiência. Por isso, no Cânon, aquele plus que a liberdade prática possuía na Dialética e que era derivado da transcendental, não pode ser afirmado (CARNOIS, 1987, p.29-30). Deste modo, a realidade objetiva da liberdade prática não pode ser objeto de uma certeza apodítica, por mais que ela queira dar-se na experiência. Sendo assim, ela fica situada entre transcendental e a natureza, não passando de uma pseudoliberdade. Nas palavras do próprio Carnois,

\footnotetext{
uma liberdade revelada somente na experiência corre o risco de ser nada mais que uma ilusão. Sob tal condição, o que poderia autorizar-nos afirmar a realidade inteligível da liberdade? A liberdade prática permanece tão estritamente conectada à natureza (com a qual pode ser até mesmo confundida) a ponto de não permitir-nos levantarmos acima da natureza para o reino onde a verdadeira liberdade reina (CARNOIS, 1987, p.31).
}

Portanto, a liberdade prática permanece dividida entre dois caráteres, sendo parte natureza, parte uma realidade inteligível não comprovada. $O$ primeiro caráter estaria atrelado às leis pragmáticas e, o segundo, às leis morais (CARNOIS, 1987, p.31).

Passamos agora a algumas breves considerações a respeito da interpretação de Carnois e apresentaremos elementos que ajudem na solução dos três problemas levantados no início. De nosso ponto de vista, em que pesem as dificuldades encontradas no texto para conciliar a Dialética com o Cânon, não há dúvidas de que este deve ter sido escrito, senão depois, pelo menos contemporaneamente à Dialética. No prefácio da segunda edição da $K r V$ que ocorrera em 1787, portanto já às vésperas da publicação da $K p V$, em momento algum Kant menciona problemas com a teoria desenvolvida na Primeira crítica. Muito pelo contrário, ele se mostra confiante no resultado do seu trabalho, a ponto de escrever no prefácio B: "em pontos isolados cada exposição filosófica é vulnerável [...] Entretanto, a estrutura do sistema, considerada como unidade, não corre com isso o mínimo perigo ( $K r V$, B XLIV). Além disso, todo o conteúdo do Cânon pressupõe a Filosofia especulativa. A esse respeito Kant é muito claro quando escreve acerca dos limites do âmbito especulativo e da necessidade de apresentar um uso prático para a razão $(K r V$, B82325), demonstrando que já havia desenvolvido a Filosofia especulativa quando 
passara a tratar da Filosofia prática. Além disso, Kant define a liberdade prática nos mesmos termos em ambos os textos (definição essa mantida na $K p V$ e na $M S$ ), embora ainda precisemos explicar por que, no Cânon, ela é uma das causas naturais. Portanto, a questão da anterioridade cronológica do Cânon é difícil de ser sustentada.

Considerando então a contemporaneidade dos textos, é pouco provável que, se houvesse contradição entre eles, Kant não a teria percebido, relegando assim a liberdade prática um conceito empírico e ambíguo, tal como sugere Carnois. Conforme Esteves, “[...] se isso de fato correspondesse às intenções de Kant, então, dizer que a sua concepção de liberdade prática é "ambígua" seria empregar um eufemismo (ESTEVES, 2009, p. 61). Em B829, logo após diferenciar as leis morais das pragmáticas, Kant ressalta, em nota, que os conceitos práticos, tendo a ver com os objetos do agrado ou desagrado, do prazer ou do desprazer, pelo menos indiretamente relacionam-se com os sentimentos, e por isso tais conceitos não pertencem ao conjunto da Filosofia transcendental que tem a ver apenas com conhecimentos puros a priori ${ }^{3}$. Mas, mesmo assim Kant quer manter-se o mais próximo possível da Filosofia transcendental, justamente para que o prático não seja confundido com o empírico ou com a liberdade psicológica. Com isso Kant está sugerindo os conceitos práticos são de uma natureza singular, pois estão relacionados com a ação humana, com o próprio arbítrio. De fato, aqui o desafio de Kant é dar um passo além do especulativo, mas sem cair no empírico. Ou ainda, que a liberdade seja conhecida na experiência "como uma das causas naturais", mas sem ser reduzida à mera causalidade natural, mantendo assim o plus de sua natureza inteligível.

Outro aspecto que julgamos deficitário na interpretação de Carnois diz respeito à ideia de que a liberdade prática se mostraria por meio de uma apreensão psicológica imediata. E aqui já queremos deixar clara nossa posição em relação ao segundo problema, a saber, que a liberdade seria conhecida na experiência. Ora, a Filosofia kantiana sempre opera a partir de conceitos, procurando afastar tudo aquilo que é de caráter psicológico. Neste sentido, dizer que a experiência demonstra a liberdade através de uma apreensão psicológica, significaria admitir que os sentidos podem atestar algo que é de natureza noumênica, contrariando assim o método com que a Filosofia kantiana opera, que é sempre através de uma análise dos conceitos. Mesmo se tomássemos a consciência da lei moral (determinada por Kant na Segunda crítica como se fosse um factum da razão) como uma apreensão imediata, veríamos que ainda assim Kant não a considera uma apreensão psicológica, mas um factum a priori ( $K p V$, AA 05: 43), do que se depreende que uma apreensão psicológica não pode servir de critério para determinar o inteligível. Por isso, quando Kant

\footnotetext{
3 Semelhante afirmação é feita no final da introdução "B". Ali Kant procura definir o âmbito da Filosofia transcendental afirmando que nela não poderá entrar nenhum conceito contendo algo empírico e que o seu conhecimento a priori é inteiramente puro. Por isso, embora os conceitos fundamentais da moralidade sejam a priori, não pertencem à Filosofia transcendental, pois ainda que não assumam positivamente como fundamento dos seus preceitos os conceitos de prazer e desprazer, desejos e inclinações (que são todos de origem empírica), tem que introduzi-los no seu sistema como obstáculo a ser vencido ou como estímulo que não deve ser transformado em motivo ( $K r V$, B28-29).
} 
menciona, no Cânon, que a liberdade pode ser conhecida na experiência ${ }^{4}$, parece sugerir que, o fato de existir os imperativos da razão, as leis morais, isso nos permitiria estabelecer algum critério para atribuir realidade prática a algumas substâncias no mundo fenomenal em que o sujeito transcendental, considerado na Dialética um conceito inteligível e vazio, poderia ter realidade objetiva. O próprio Kant chega a sugerir onde seria possível de se perceber o comando absoluto das leis morais, ao afirmar: "posso com justiça pressupor esta proposição não só me reportando às provas dos mais esclarecidos moralistas, mas também ao juízo moral de cada ser humano, desde que pretenda pensar claramente uma tal lei" ( $K r V$, B835). Sendo assim, uma ação baseada nos imperativos, seria uma espécie de critério para atribuirmos liberdade ao agente. De fato, Esteves pensa que, embora possamos encontrar demonstrações na experiência de que os imperativos da razão são reais, eles sempre serão analisados tendo por referência os próprios conceitos, os quais são aceitos intersubjetivamente e não dependem de uma introspecção psicológica, o que os tornaria totalmente dependentes da empiria e estariam à mercê de juízos puramente subjetivos. Por isso, segundo ele, o agir segundo imperativos seria " [...] compreendido como um recurso a certas maneiras de usar e compreender determinados conceitos intersubjetiva e publicamente acessíveis" (ESTEVES, 2009, p. 51). Esta "prova" da liberdade prática (deduzida da experiência via conceitos) apresentada no Cânon, Kant não poderia tê-la feito na Dialética, já que ali se tratava do âmbito teórico, o que significaria violar os fundamentos por ele estipulados na Analítica. Porém, dado que pretenderia demonstrá-la no Cânon, assume-a antecipadamente na Dialética como um postulado, uma hipótese. Portanto, sabendo que iria dar um "prova" no Cânon via experiência, Kant já antecipa na Dialética um conceito positivo para a liberdade prática, sugerindo que as ações morais poderiam manifestar seus "sinais" através do dever e dos imperativos da razão. E com isso, aquilo que era somente uma ideia transcendental, poderia ser pensado como podendo exercer uma causalidade efetiva e deixar sua marca no mundo dos fenômenos.

\section{Allison: a compatibilidade entre o Cânon e a Dialética e a ambiguidade da liberdade prática}

Assim como Carnois, Allison afirma que a liberdade prática é ambígua e tal ambigüidade é encontrada tanto no Cânon quanto na Dialética. Só que, diferentemente de Carnois, ele pensa não haver inconsistência entre os dois textos, afinal ambos operam com o mesmo conceito de liberdade, seja a prática, seja a transcendental.

Segundo Allison, já desde a Dialética a liberdade prática necessita de uma causalidade incompatibilista para mostrar seus efeitos na natureza. Contudo, se na Dialética ambas as liberdades estavam interligadas, no Cânon Kant deixa de lado a

\footnotetext{
4 Kant repete esta tese nos mesmos termos na Terceira crítia: “Tal é a ideia de liberdade, cuja realidade, como espécie particular de causalidade (da qual o conceito seria transcendente de um ponto de vista teórico), deixa-se demonstrar mediante leis práticas da razão pura e em ações efetivas adequadas àquelas, por conseguinte na experiência". ( $K U, \mathrm{AA}$ 05: 468).
} 
liberdade transcendental devido ao contexto prático do texto. Neste quesito, Beck, por exemplo, afirma que Kant não diz que a liberdade prática poderia manter-se sem a transcendental, apenas que esta questão não concerne ao campo prático, o qual demanda da razão nada mais que uma regra de conduta (BECK, 1960, p.190, nota 40). Contudo, Allison salienta que Beck não percebe que a contradição poderia ser evitada mesmo se o Cânon afirmasse que a liberdade prática poderia manter-se sem a transcendental, pois não há, no Cânon (e também na Dialética), uma exigência de que a liberdade prática não possa prescindir da liberdade transcendental. $O$ que percebemos ali é uma dependência apenas conceitual e não ontológica. De fato, a liberdade transcendental é apenas uma ideia reguladora que lançamos mão para atribuir espontaneidade ao agente racional. "[...] Kant está afirmando apenas que é necessário apelarmos para a ideia transcendental de liberdade no sentido de nos concebermos como agentes racionais praticamente livres, não que nós devemos, na realidade, ser livres em sentido transcendental para sermos livres em sentido prático" (ALLISON, 1990, p. 57). Em segundo lugar, Kant também não estaria dizendo, no Cânon, que a liberdade prática, sem a transcendental, seria apenas uma concepção compatibilista inadequada. Portanto, no entender de Allison, quer na Dialética, quer no Cânon, seria legítimo Kant ter deixado de lado a liberdade transcendental, já que se tratava apenas de uma ideia reguladora.

A suposição de incompatibilidade entre a Dialética e o Cânon deve-se ao fato de que a liberdade prática apresentada em ambos os textos é ambígua. Daí que somos levados, devido a esta ambigüidade do conceito, a pensar que os textos seriam incompatíveis, o que não é correto, no entender de Allison. Tal ambigüidade não seria entre uma concepção compatibilista e outra incompatibilista (na Dialética e no Cânon respectivamente) de liberdade como comumente os pesquisadores tendem a sugerir, mas uma ambigüidade oriunda de duas visões incompatibilistas. Numa primeira versão a liberdade prática seria considerada uma espécie de liberdade transcendental, um primeiro começo, só que aplicada à vontade humana. Na segunda versão teríamos uma forma distinta, limitada e genuinamente incompatibilista de liberdade (ALLISON, 1990, p. 54). Nesta segunda versão, a liberdade, "mais especificamente é uma forma atribuível a agentes racionais finitos, sensivelmente afetados, mas não determinados tais como nós mesmos" (ALLISON, 1990, p. 58). Embora haja um predomínio da primeira versão na Dialética e da segunda no Cânon, no entender de Allison cada uma das versões poderia ser aplicada indistintamente em cada um dos textos.

No que tange à ambiguidade da segunda versão (do Cânon), Allison parte da hipótese de que, para a razão exercer uma genuína causalidade sobre o mundo dos fenômenos, a liberdade prática deveria ser tomada num sentido incompatibilista, a fim de não ser subsumida pela causalidade natural (embora ele interprete o incompatibilismo nos termos de uma liberdade relativa, isto é, dependente dos estímulos sensíveis). Isto significa dizer que, de alguma forma, teríamos que encontrar marcas na experiência desse caráter inteligível da razão. Deste modo, haveria uma dependência da razão de uma causa que vem da sensibilidade, de um estímulo sensível tal como o desejo, por exemplo, mas tal dependência não seria uma dependência causal. Trata-se da famosa tese da incorporação defendida por Allison, a

PELLIZZARO, Nilmar. Liberdade: uma relação entre cânon e dialética na Crítica da razão pura. Griot : Revista de 
qual procura pensar a ação de um agente racional de modo a conciliar o âmbito da razão (regras racionais, imperativos) com as inclinações (motivações, desejos, etc.). $O$ agente, mesmo naquelas ações fundadas em desejos, não seria determinado de maneira totalmente mecanicista pela simples força do desejo, pois um desejo, por si só e independente de qualquer regra fornecida pela razão, não poderia realizar uma ação racional (em sentido amplo e não apenas moral), pois é apenas um mero impulso cego. Por outro lado, as regras/imperativos, isoladamente não teriam força para realizar qualquer ação, uma vez que são regras abstratas e não móbeis de ações. Por isso, as regras/imperativos da razão e os impulsos da sensibilidade precisariam cooperar mutuamente para levar a cabo uma ação racional. Assim, as regras/imperativos forneceriam apenas o critério ou fundamento racional para guiar a ação do arbítrio, mas em si, enquanto simples regras da razão, não mobilizam nada (ALLISON, 1990, p. 49-50).

Deste modo, para que uma ação seja uma causalidade da razão, a inclinação, enquanto móbil da ação, deverá ser incorporada numa máxima, a qual deve ser guiada por uma regra/imperativo racional. Isto é, o arbítrio deve incorporar em sua máxima um móbil sensível, a fim de exercer a sua causalidade no mundo dos fenômenos, sem o qual a razão ficaria presa nela mesma (ALLISON, 1990, 39-40). Pode-se dizer que, uma razão sem um móbil sensível, seria uma razão estéril do ponto de vista prático, uma vez que ela nos fornece somente o princípio racional da ação; por sua vez, um móbil, sem uma regra que direcione o agente, seria um impulso cego, desejando qualquer coisa. Portanto, a liberdade prática só poderia ser pensada a partir de sua dependência dos móbeis da sensibilidade, de modo que ela teria uma independência relativa em relação às inclinações, mas não uma independência absoluta. Seria ainda uma liberdade não totalmente pura, mas semicrítica, o que configuraria uma heteronomia do ponto de vista de uma teoria moral. (ALLISON, 1990, p. 65).

A partir disso percebemos que a ambigüidade desta liberdade prática se deve à sua independência relativa, a qual, de alguma forma sempre a torna prisioneira da sensibilidade para mobilizar uma ação. É por isso que, pensada nestes termos, esta liberdade seria tomada como uma das causas naturais conhecida na experiência. Por seu caráter empírico ela pode ser considerada uma causa natural, enquanto que, por meio do inteligível, não poderá ser redutível à experiência, mas mantém um plus que a diferencia do mundo concatenado fenomenicamente. Mas, note-se que este plus, fornecido pela liberdade transcendental, verifica-se em função de que esta é uma ideia reguladora, não sendo necessária uma pressuposição ontológica a seu respeito para que a liberdade prática disponha de um caráter de espontaneidade (fornecendo regras e imperativos) da razão. Portanto, a liberdade prática estaria situada entre a natureza e o inteligível, assim como já observara Carnois. Contudo, diferente deste, Allison vê uma saída para o problema ao mostrar que a liberdade transcendental é um conceito apenas regulador.

Com isso podemos perceber que, enquanto a liberdade transcendental possui uma independência absoluta em relação à sensibilidade, a liberdade prática teria uma independência relativa. Desta forma, embora o texto do Cânon não seja considerado por Allison como anterior ao da Dialética, ele ainda é insatisfatório em 
termos de uma moralidade madura, demonstrando que houve posteriormente uma mudança no pensamento de Kant a partir da Fundamentação. Não obstante, apesar de Kant só ter conseguido estabelecer uma liberdade prática relativa, não haveria incompatibilidade entre a Dilética e o Cânon, já que a liberdade prática em ambos os textos manteria um caráter ambíguo, embora não fique claro para o leitor como Allison configura tal ambiguidade na Dialética.

Passamos agora a uma análise da proposta de Allison. A primeira dificuldade de sua interpretação reside na questão da liberdade transcendental. $\mathrm{O}$ tom regulador que Allison lhe atribui faz com que ela não seja ontologicamente necessária. Ora, pelo texto da Dialética Kant chega à conclusão de que ela não poderia ser comprovada, mas também não poderia ser negada como algo improvável. Não obstante, como estava indissoluvelmente conectada à liberdade prática, a sua supressão necessariamente extinguiria a possibilidade desta última. Por isso, mesmo não podendo demonstrá-la na Dialética, Kant a pressupõe, porque tinha a intenção de dar uma prova indireta a seu respeito no âmbito prático, por meio de uma prova da liberdade prática através da experiência, em que se poderia verificar a existência dos imperativos da razão. Lembremos que, na Dialética, uma das questões tratadas por Kant diz respeito à imputabilidade. E, conforme Pavão, se concebermos a liberdade transcendental como um conceito meramente regulador, teremos problemas em admitir suposta imputabilidade. Por isso ele questiona: "se a liberdade transcendental fosse apenas uma ideia regulativa, com vistas a nos concebermos como seres praticamente livres, então o que significaria a nossa auto-concepção de seres praticamente livres?" (PAVÃO, 2002, p. 188). Lembremos que Kant afirma que somos seres com um arbitrium liberum e que por meio das leis da razão podemos nos elevar acima das leis da natureza. Neste caso, a liberdade precisa ser algo real, do contrário não passaríamos de meros autômatos, quer sob o aspecto materiale, quer sob o spirituale, como Kant esclarece na Segunda crítica. (KpV, AA 05:97).

Quanto à liberdade prática, a ambiguidade que lhe é atribuída por Allison a torna demasiado dependente de um estímulo sensível e acaba por subsumi-la na causalidade natural, tornando-a deveras limitada. Retomemos o excerto B28-9 recém citado da $K r V$ em que Kant diz que, na Filosofia transcendental, não poderia haver qualquer conceito empírico, porque se trata de uma Filosofia pura. Ao passo que, os conceitos da moralidade seriam a priori, mas não puros e por isso não pertenceriam à Filosofia transcendental, porque tais conceitos, mesmo não assumindo positivamente como fundamento dos seus preceitos os conceitos de prazer e desprazer, desejos e inclinações (que seriam todos de origem empírica), teriam que introduzi-los no seu sistema como obstáculo a ser vencido ou como estímulo que não deveria ser transformado em móbil. Ou seja, a liberdade, em sendo um conceito da moralidade, mesmo não sendo um conceito puro e sim a priori (porque está relacionado com o empírico, mas não se confunde com ele) não poderia assumir nenhuma inclinação como móbil, demonstrando que não era a intenção de Kant apresentar um conceito ambíguo ou relativo acerca da liberdade. E lembremos que a introdução "B" fora escrita em 1787, dois anos após a publicação da Fundamentação, já às vésperas da publicação $K p V$, obras em que aparece a teoria moral amplamente desenvolvida.

PELLIZZARO, Nilmar. Liberdade: uma relação entre cânon e dialética na Crítica da razão pura. Griot : Revista de 
Conforme Esteves, por um lado Allison não quer que nenhum móbil sensível torne necessária uma ação da razão - que é portadora da liberdade prática. Mas, por outro lado, quando um agente executa ou mesmo omite uma ação, ele o faz necessariamente por meio de um estímulo sensível qualquer, de modo que este estímulo torna-se uma condição imprescindível (condição sine qua non) para que determinada ação aconteça, pois a razão, por si só, não poderia mobilizar a vontade do agente. $O$ problema desta forma de liberdade prática é que um agente sempre será dependente de um estímulo sensível para levar a cabo sua ação, o que implica na impossibilidade de se pensar uma liberdade contra-causal. E uma liberdade nesses termos é o que se exige de uma ação racional no verdadeiro sentido incompatibilista, isto é, uma liberdade em termos absolutos, com total independência para iniciar uma nova série no tempo. Portanto, o conceito de liberdade relativa a que chega Allison é insuficiente para se pensar num sentido verdadeiramente incompatibilista, e assim, a afirmação kantiana de que a supressão da liberdade transcendental aniquilaria toda a liberdade prática, só pode fazer sentido quando aplicada a um conceito de liberdade genuinamente incompatibilista. Por isso, conclui Esteves, há uma falta de clareza por parte de Allison quanto ao que significa liberdade em sentido incompatibilista na interpretação da liberdade prática (ESTEVES, 2009, p. 63-4).

Além disso, Allison também não é muito claro quanto ao que seria esta forma de ambigüidade no texto da Dialética. Como ele mesmo expressa, há duas formas de ambigüidades, uma predominando no Cânon e outra na Dialética, embora cada uma delas possa ser encontrada em ambos os textos. O curioso é que o próprio Allison afirma que há apenas um conceito de liberdade prática, que pode ser encontrado tanto na Dialética quanto no Cânon. Ora, por um lado teríamos apenas um conceito de liberdade nos dois textos; por outro, duas formas de ambiguidades, o que nos leva a concluir que há inconsistências na sua interpretação. Portanto, concluir por um caráter ambíguo ou relativo da liberdade não nos parece ser a interpretação apropriada, o que nos conduz a buscar uma forma de pensar a liberdade que mantenha a independência absoluta.

\section{Esteves: a compatibilidade entre o Cânon e a Dialética e o hibridismo da liberdade prática}

Esteves acha possível conciliar as afirmações do Cânon com a Dialética, apontando que o conceito de liberdade prática é um conceito híbrido, mas não empírico, como sugere Allison, e que ela possui uma independência absoluta em relação aos estímulos que vêm da sensibilidade. Ela teria o mesmo sentido em ambos os textos e seria definida sempre contra o pano de fundo da afecção sensível, ou seja, sempre contra as inclinações e desejos. Isto porque ela é uma propriedade de uma substância existente no interior da série fenomenal (o arbítrio humano), diferente da liberdade transcendental cosmológica que é tratada na cosmologia racional como uma causa originária fora da série. Daí que tanto o Cânon quanto a Dialética concordam em atribuir um ingrediente psicológico à liberdade prática. Conforme Kant observou na Dialética, "a idéia transcendental da liberdade, na verdade, está longe de constituir o conteúdo total do conceito psicológico desse nome, que é em 
grande parte empírico" (CRP, B476). Note-se, porém, que para Esteves nem mesmo o fato da liberdade prática conter notas empíricas impediu Kant de considerá-la num sentido incompatibilista, como uma causalidade absoluta da razão, pois ela mantém uma espontaneidade necessária à imputabilidade da ação. Afinal, o próprio Kant afirma $(K r V, B 563)$ que, embora a questão da possibilidade da liberdade prática diga respeito à psicologia, dela tem que se ocupar, assim como da sua solução, a Filosofia transcendental. (ESTEVES, 2009, p. 46-8).

Conforme Esteves, este conceito de liberdade prática (contendo notas empíricas) é retomada por Kant no Cânon em sintonia com a Dialética. Neste sentido, o autor comenta que "[...] Kant está mais uma vez exprimindo a consciência de que tal conceito é híbrido e não reduzindo-o a algo que possa ser estabelecido como um fato psicológico mediante introspecção" (ESTEVES, 2009, p. 48). Por ser híbrido, ele contém uma nota empírica, mas, ao mesmo tempo, não pode ser redutível à experiência, já que contém um aspecto transcendental a priori dado pela liberdade transcendental, capaz de fornecer um fundamento para tornar a ação espontânea e imputável. Perceba-se que, o que Esteves chama de nota empírica da liberdade, tem a ver com o fato de ela estar em contato com a sensibilidade (afinal ela é atribuída a seres limitados como nós, com um arbitrium liberum), e por isso mostra seus sinais através dos imperativos da razão. Mas isso não significa uma liberdade ambígua ou limitada como propunha Allison, mas uma liberdade absoluta, com total espontaneidade frente aos estímulos da sensibilidade e não dependente destes.

Esteves continua dizendo que a liberdade transcendental também possui traços comuns em ambos os textos, significando que as afirmações de Kant a este respeito são consistentes. Embora a liberdade prática contenha uma nota a priori dada pela transcendental, elas não se confundem. $O$ que há entre elas é uma distinção de gênero e espécie. Assim, a liberdade transcendental conteria o pensamento de um agente causal em geral, capaz de um primeiro começo em sentido absoluto. Já a liberdade prática seria uma espécie desta causalidade absolutamente livre, a qual conteria, por um lado, a espontaneidade que a mantém ligada à liberdade transcendental; por outro, uma diferença específica no sentido de que o agente causal é concebido como estando no interior da série fenomenal. Contudo, observa Esteves, a liberdade prática existente na série não pode ser rebaixada a uma 'mera causa natural', já que ela contém aquele elemento da espontaneidade da liberdade transcendental absoluta. Ela é um conceito relacional (liberdade de), de modo que a possibilidade de atribuí-la a um agente causal inteligível depende de que tal agente esteja em conexão com o mundo sensível. É por isso que não iremos encontrar nenhum conceito adequado de liberdade em seres como Deus, afinal, diferente dos seres humanos, suas ações não são vistas dentro da série. (ESTEVES, 2009, p. 48- 49).

Como apontamos nas críticas a Carnois, Esteves considera que o agir segundo imperativos deve ser tomado como o critério empiricamente acessível para atribuirmos liberdade prática a determinados agentes (que possuem um arbitrium liberum) no mundo fenomenal, sendo o método conceitual discursivo da Filosofia a forma intersubjetiva e pública de se verificar na experiência a presença dos imperativos. 
(ESTEVES, 2009, 51). Assim, a liberdade poderia ser 'provada na experiência' somente no âmbito prático, permanecendo um conceito transcendente no âmbito teórico. Por isso, Dialética e Cânon concordam em que, pelo fato de não se ter um critério para o seu uso, a liberdade transcendental permanece um problema para a razão, seja em seu sentido cosmológico, seja em seu sentido crítico ${ }^{5}$. Não obstante, no Cânon ela é asserida ao se poder admitir a existência de imperativos morais que determinam o arbítrio a priori e de modo absoluto. Conforme Esteves, "[...] o Cânon é o lugar em que Kant começa a tirar partido de seu diagnóstico crítico sobre as ilusões da metafísica dogmática no uso teórico da razão, fundando, então, algo assim como uma "metafísica prático-dogmática sem dogmatismo" (ESTEVES, 2009, p. $53)$.

Passamos agora à solução do terceiro problema, a saber, se a liberdade prática do Cânon seria mesmo "uma das causas naturais" e entraria em contradição com a Dialética. Esteves interpreta que razão atuaria no interior da natureza, mas sem ser subsumida nela, mantendo sua especificidade, como uma força produtiva com regras distintas e irredutíveis aos princípios naturais, de modo a continuar sendo uma liberdade em sentido incompatibilista. Neste sentido, Kant estaria afirmando que

[...] conhecemos por experiência a causalidade da razão e da liberdade, porque temos critérios empiricamente acessíveis, a saber, o agir segundo imperativos, que permitem assinalar a sua realidade como uma das causas na natureza, mas em concorrência com a causalidade natural quanto à autoria de determinados efeitos no mundo sensível, a saber, ações como algo imputável (ESTEVES, 2009, p.55).

Note-se que a causalidade da razão seria uma causalidade entre as causas da natureza, mas não uma 'mera causalidade natural', já que em seu efeito poderia ser percebida uma especificidade que a distingue das demais causas da natureza. Seria uma causa natural no sentido de que seus efeitos seriam visíveis no mundo fenomênico, mas a sua causalidade estaria em concorrência com as demais causas naturais. Tal causalidade seria visível pelos critérios intersubjetivamente aceitos, tais como o dever que provém dos imperativos da razão. Ela seria uma causalidade genuinamente incompatibilista e com uma espontaneidade absoluta. O que possibilitou Esteves defender tal tese foi uma análise do texto kantiano a partir de uma incursão pelo Deutsches Wörterbuch von Jacob und Wilhelm Grimm, em que ele percebeu que a frase do Canon "como uma das causas naturais" (als eine von den

\footnotetext{
5 Esteves distingue entre o sentido cosmológico e o sentido crítico da liberdade transcendental. O primeiro seria tratado no contexto da solução da terceira antinomia e introduzido pelo filósofo dogmático, defensor da tese, para dar conta da totalidade das condições de todo o condicionado dado no mundo dos fenômenos. Neste sentido, a liberdade seria um poder de iniciar um estado independente de condições temporais, um primeiro começo ao qual não se poderia referir nenhum objeto no mundo dos fenômenos. Este seria um conceito apenas logicamente possível que permanece um problema para a razão. Já o sentido crítico seria concebido como uma causalidade que atua no tempo e independentemente da determinação de condições antecedentes - teria a ver com uma causa inteligível no interior da série fenomenal, um sujeito transcendental " $x$ " que permanece uma fórmula vazia, já que não podemos ter dele uma intuição não sensível. Assim como a cosmológica, esta última permaneceria também como um problema para a razão teórica (ESTEVES, 2009, p. 49-50).
} 
Naturursachen), poderia ser substituída por "como uma causa entre as naturais" (als eine unter den Naturursachen). Neste caso, o termo "von", seria perfeitamente substituível por "unter", e assim o sentido seria totalmente diferente, pois Kant estaria afirmando que haveria entre as causas da natureza uma de caráter especial, mas que não poderia ser subsumida à natureza. Na expressão: "entre os cegos, quem tem um olho é rei" é possível perceber-se que, embora sendo considerado um membro do grupo cego, este indivíduo que possui um olho se diferencia dos demais, isto é, ele é um cego entre os cegos, mas com uma nota especial, isto é, com um olho que lhe permite enxergar. Assim também seria a liberdade. Ela seria uma causa de tipo especial entre as causas da natureza. Portanto, segundo Esteves o texto do Cânon poderia ser reescrito da seguinte forma: "conhecemos a liberdade prática através da experiência como uma entre as causas naturais, a saber, uma causalidade da razão na determinação da vontade". (Cf. ESTEVES, 2014, p. 364). Curiosamente às vezes os intérpretes não se dão conta de que na própria Dialética há um excerto praticamente idêntico a este do Cânon, no qual Kant situa claramente a causalidade pela liberdade entre as causas naturais, mas lhe atribui um caráter de espontaneidade absoluta. E aqui em vez do termo "von" Kant usa "unter", ficando ainda mais clara esta caracterização. "[...] dentre as causas naturais também existem algumas que possuem um poder que é unicamente inteligível enquanto a determinação do mesmo para ação jamais repousa sobre condições empíricas, mas sim sobre exclusivos fundamentos do entendimento". ( $\mathrm{KrV}$, B573). Assim, considerando legítima esta substituição do termo "von" por "unter", poderíamos concluir que o sentido do excerto da Dialética é o mesmo daquele do Cânon, e que, portanto, não haveria nenhuma contradição entre os textos. Pelo contrário, no Cânon Kant estaria apenas retomando uma ideia anterior e confirmando que a liberdade prática possui uma espontaneidade absoluta, muito embora esteja entre as causas naturais.

Em relação à solução do primeiro problema (em que Kant afirmara no Cânon que, em virtude deste contexto ser exclusivamente prático, deixaria de lado a liberdade em seu significado transcendental, a qual não poderia ser empiricamente pressuposta como fundamento explicativo dos fenômenos, constituindo antes um problema para a razão), Esteves considera que se trata de um desafio lançado por Kant a um possível adversário (o filósofo dogmático) que eventualmente tinha a intenção de assumir a posição contrária. $O$ defensor da antítese poderia perguntar: "se aquilo que se chama liberdade relativamente a impulsos sensíveis não poderia ser, por sua vez, natureza, relativamente a causas eficientes mais altas e mais remotas"? ( $K r V$, B831). Ante essa possibilidade levantada pelo filósofo dogmático, Kant o adverte que esta "é uma questão meramente especulativa, que pode ser posta de lado na medida em que nosso propósito está voltado para o fazer ou o deixar de fazer" (KrV, B831). De fato, Kant não está simplesmente deixando de lado a questão da liberdade transcendental e considerando que a liberdade prática poderia manter-se em pé sem ela. "A pergunta se a liberdade prática está de fato fundada na transcendental, e não, em última análise, na natureza, não é em si mesma estranha ao prático ou uma pergunta especulativa, mas pode ser colocada em termos especulativos, e é exatamente nesses termos que Kant a está considerando" (ESTEVES, 2009, p. 56). Por isso, Kant está analisando a questão na medida em que 
ela seria colocada pelo defensor da antítese que sustenta que tudo é natureza. Mas Kant não está aqui afirmando que em si mesma, a questão "se aquilo que é liberdade relativamente aos impulsos sensíveis não poderia ser, em última análise, natureza", não é irrelevante. Pelo contrário, “[...] essa questão é irrelevante na medida em que é posta pelo filósofo especulativo como tentativa de invalidar a asserção prática da liberdade" (ESTEVES, 2009, p. 56). Como vimos na terceira antinomia, este filósofo cai em contradição ao querer estender as condições do conhecimento da natureza a objetos que extrapolam o âmbito da natureza.

Ao mesmo tempo em que assume posição contra o defensor da antítese, Kant estaria se posicionando contra o defensor da tese da terceira antinomia, postulando que a liberdade prática pode ser conhecida por experiência como uma causa entre as naturais. Esteves observa que Kant não está renunciando ou mesmo banindo a liberdade transcendental da Filosofia por ela constituir um problema no seu aspecto teórico. Muito pelo contrário, ele está banindo da Filosofia prática apenas aquilo que deve permanecer como um problema da filosofia especulativa. Em outros termos, "Kant está querendo dizer que a liberdade transcendental de fato pertence à Filosofia prática, mas não como um problema, como o é e tem de permanecer para a filosofia especulativa" (ESTEVES, 2009, p. 57). Assim, Kant não está dissociando as duas liberdades, como pensa Carnois, pois, do contrário, se a liberdade prática fosse pensada num sentido compatibilista, nem mesmo seria necessário Kant introduzir a discussão acerca da liberdade transcendental, já que ela não faria qualquer diferença para uma liberdade prática assim concebida. Por isso, diante defensor da antítese, a questão de Kant era rejeitar a negação da liberdade; diante do defensor da tese, seu interesse está em rejeitar a afirmação teórico-especulativa da liberdade. Ou seja, o desafio diante do defensor da tese é mostrar o lugar legítimo da liberdade, que é o âmbito prático. De fato, Kant quer antecipar-se ao filósofo dogmático que se arrogue ter a última palavra sobre a liberdade em sentido transcendental, como se ela só tivesse validade se pudesse ser provada a partir de premissas teórico-especulativas. (ESTEVES, 2009, p. 58).

Portanto, a conclusão de Esteves é que não é possível uma prova da liberdade transcendental do ponto de vista especulativo. Isto quer dizer que

[...] a questão especulativa da liberdade transcendental é irrelevante do ponto de vista prático, porque este último nem carece de uma confirmação nem precisa temer uma refutação de suas pretensões por parte da filosofia especulativa. Pois, como o filósofo especulativo não pode se pronunciar sobre o que está além da experiência, tudo o que ele disser a respeito da liberdade será simplesmente irrelevante (ESTEVES, 2009, p.59).

Portanto, a conclusão a que chegamos a partir das três interpretações é que a teoria de Esteves nos permite perceber uma maior coerência e unidade entre os textos da Dialética e do Cânon, evidenciando que este último fora escrito logo após a Dialética e que era a intenção de Kant apresentar a face teórica e prática da razão pura numa unidade. Kant mostra, na Dialética, os limites da razão em pensar o inteligível no campo teórico e, mesmo considerando que a demonstração prática da liberdade no Cânon tenha sido insatisfatória (já que uma melhor formulação desta 
dedução teria sido elabora na $K p V$ com o factum da razão), é notável seu intento de elaborar uma teoria que nos permitisse conhecer a liberdade no âmbito prático e assim uma crítica da razão estaria completa. Disso conclui-se, contrário ao que pensa Carnois e Allison, que a teoria moral do Cânon, ainda que não totalmente lapidada, não era uma teoria pré-crítica, seja porque Kant aponta que a necessidade interna presente nas leis morais é a força suficiente para nos obrigar a agir, seja porque a liberdade prática nos permite uma ação com total independência dos impulsos da sensibilidade e motivados somente pelos imperativos da razão, isto é, pelas leis morais. 


\section{Referências bibliográficas}

ALLISON, Henry E. Kant's Theory of Freedom. New York: Cambridge University Press, 1990.

ALMEIDA, Guido Antônio de. Liberdade e moralidade segundo Kant. In: Analytica, v.2, n.1, p.175-202, $1997 . \quad$ Disponível em: https://revistas.ufrj.br/index.php/analytica/issue/view/66/showToc.

BECK, Lewis White. A Commentary on Kant's Critique of Practical Reason. Chicago: University of Chicago Press, 1960.

CARNOIS, Bernard. The Coherence of Kant's Doctrine of Freedom. Chicago: The University of Chicago Press, 1987.

ESTEVES, Julio. A Liberdade no Cânon da Razão Pura: uma interpretação alternativa. In: Kant e-Prints, v. 4, n.1, p. 43-65, 2009. Disponível em: https://www.cle.unicamp.br/eprints/index.php/kant-e-prints/issue/view/49.

. The alleged incompatibility between the concepts of practical freedom in the Dialectic and in the Canon of the Critique of Pure Reason. In: Kant-studien, v. 105 (3), p. 336-371, 2014. Disponível em: https:/www.degruyter.com/view/j/kant.2014.105.issue3/issue-files/kant.2014.105.issue-3.xml.

KANT, I. Crítica da Razão Prática. Trad. Valério Rohden. São Paulo: Martins Fontes, 2011.

. Crítica da Razão Pura. Trad. de Valério Rohden e Udo Baldur Moosburger. São Paulo: Abril Cultural, 1980.

Crítica da Faculdade do juízo. Trad. Valerio Rohden e António Marques. $2^{\mathrm{a}}$. ed. Rio de Janeiro: Forense Universitária, 2008.

PAVÃO, Aguinaldo. Liberdade Transcendental e Liberdade Prática na Crítica da Razão Pura. In: Revista Síntese, Belo Horizonte, v. 29, n.94, p. 171-190, 2002. Disponível em: http://faje.edu.br/periodicos/index.php/Sintese/issue/view/280.

SMITH, Norman Kemp. Commentary to Kant's Critique of Pure Reason. 2. ed. Atlantic Highlands: Humanities Press International, 1996.

Autor(a) para correspondência: Nilmar Pellizzaro, Universidade Federal de Santa Catarina, Centro de Filosofia e Ciências Humanas, Universidade Federal de Santa Catarina - UFSC - Trindade, CEP 88040-970, Florianópolis - SC, Brasil.nilpellizza@gmail.com 